\title{
Modeling Rainfall Runoff Relations at Arid Catchments Using Conceptual Hydrological Modeling Approach
}

\author{
Abdulnoor A.J. Ghanim* \\ Department of Civil Engineering, Faculty of Engineering, Najran University, Najran, \\ Saudia Arabia
}

\begin{abstract}
Article Type: Article
Article Citation: Abdulnoor A.J Ghanim. Modeling rainfall runoff relations at arid catchments using conceptual hydrological modeling approach. Indian Journal of Science and Technology. 2020; 13 (03), 329-339. DOI: $10.17485 /$ ijst/2020/ v013i01/121966
\end{abstract}

Received date: March 4, 2018

Accepted date: March 28, 2019

*Author for correspondence: Abdulnoor A.J. Ghanim aaghanim@nu.edu.com $>$ Department of Civil Engineering, Faculty of Engineering, Najran University, Najran, Saudia Arabia

\begin{abstract}
Objective: To develop a simple deterministic lumped conceptual rainfall-runoff model. Methods/statistical analysis: This study developed a model based on the water balance, in which the model tracks precipitation, simulated soil water content, surface runoff, evapotranspiration, percolation, and return streamflow. The major input requirements for this model are hourly rainfall, hourly potential evaporation and the average daily streamflow record. The model is calibrated and tested using the available data collected from only one semi-arid ephemeral catchment located in the central part of Jordan. The model was optimized using Shuffle Complex Evolution (SCE.UA) optimization method. The performance of the model was evaluated using the goodness of fit measures. Findings: The simulation results obtained show that the proposed model has a good match between observed and simulated streamflow for both optimization and validation stages. Application/improvements: The good simulation results obtained indicate that the model will be useful in design of hydraulic structures and for effective management of water resources at arid and semi-arid catchments. In order to strengthen the validation and applicability of the proposed model, empirical research needs to be conducted. Further research is required to assess the predictive uncertainty associated with model parameters and other inputs.
\end{abstract}

Keywords: Hydrological Modeling, Rainfall-Runoff Relation, Streamflow Forecasting, Conceptual Model, Arid Catchments.

\section{Introduction}

In recent decades, the advent of increasingly efficient computing technology has provided hydrologists with exciting new tools for the mathematical modeling of the rainfall-runoff process. The conceptual models have a structure of interconnected storage. Compared 
with Black Box models, these models are less simple even though they may have no straightforward physical interpretation. The model defined as a conceptual if at least one of its parameters has to be calibrated [1]. These models do not simulate other hydrological variables (infiltration, groundwater level, etc.) and most of them produce a single output (streamflow). Examples of this type of models include the Stanford watershed model [2], MODHYDROLOG model [3], and IHACRES model (Identification of Unit Hydrographs and Component Flow from Rainfall, Evaporation and Streamflow data) jointly developed by the Institute of Hydrology UK and the Center for Resources and Environmental Studies in the Australian National University, and described by Jakeman et al. [4]. The daily modeling by the daily conceptual model GR4J gives a good general trend of simulated runoffs when applied on Isser catchment, Alegria, which characterized by a meditation climate [5]. Lack of data is the main obstacle to development of useful hydrological models for arid zone catchments, which is due to isolation, low population density (and thus high cost), and low economic potential of many of these area [6]. There is a pressing need to improve capability to predict the hydrological responses of arid and semi-arid catchments. Application of physically based models in arid zones catchments requires extensive physical parameters and hence more data and this is more costly and not readily available. The requirements of large data and physical parameters make the use of physically based models very limited in arid zone. According to some researchers [7], a model is a simplified representation of real world system. The best model is the one, which give results close to reality with the use of least parameters and model complexity. McIntyre et al. [8] developed simple regression models to predict flood peaks and volumes from properties of the rainfall and antecedent conditions. They found that a simple two-parameter model (regression of flow peaks and volumes to rainfall total) produced the best predictions in terms of achieving the $30 \%$ accuracy tolerance. There are, therefore, potential benefits in adopting a simple, empirical approach to modeling. It is less expensive, can provide basic insight into controls on runoff, and can be applicable to water balance and flood estimation problems.

The model proposed in this study belongs to this category of rainfall-runoff models [i.e., conceptual models]; this model to some extent satisfies the requirements for operation at arid and semi-arid ephemeral catchments. Most of conceptual models are able to provide consistent and reliable results. They seem to be very appropriate because of their low data requirements, their simplicity, and their ease of use. Moreover, they are compatible with the existing hydrological tools of the customer.

\section{Methodology}

A workable structure for the model presented in this study developed from the analysis of published research reports. The model is a conceptual spatially lumped water balance model. The model uses hourly rainfall, pan evaporation and the average daily streamflow record as input data. The outputs from this model are the hourly series of simulated streamflow hydrograph. A schematic diagram showing the structure of the proposed model is given in Figure 1. 
Evapotranspiration Precipitation

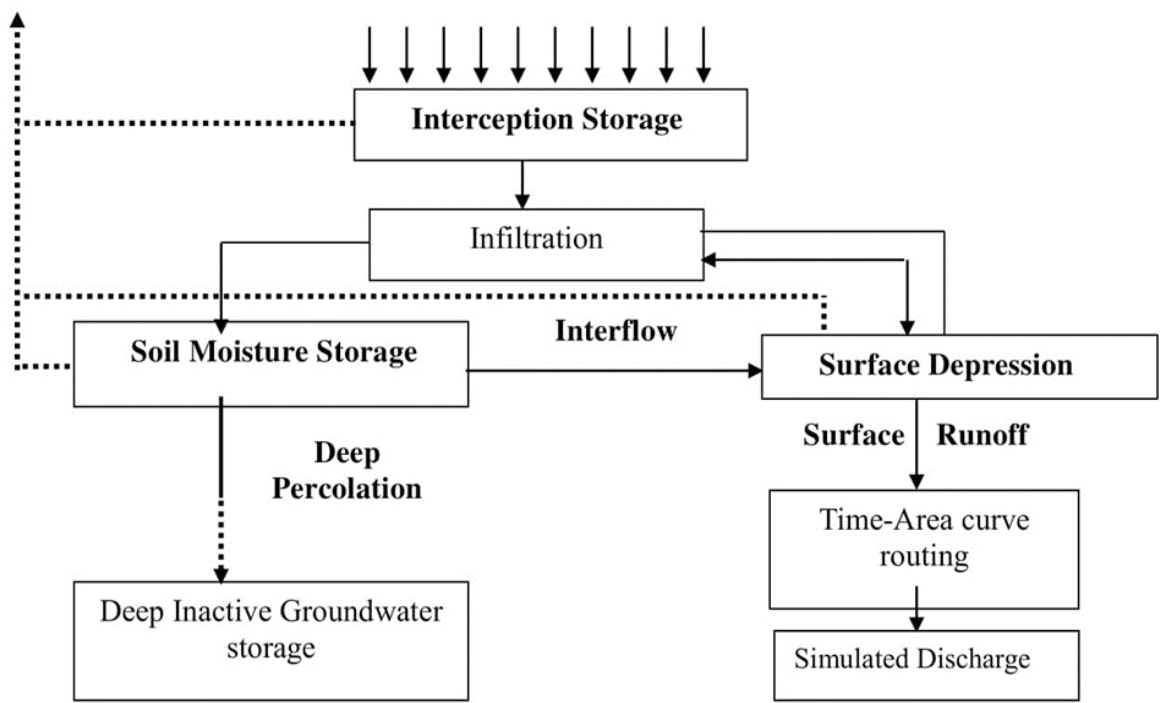

FIGURE 1. Schematic diagram of the catchment model structure.

The model is based on water balance of the land phase according to the following continuity equation:

$$
R_{a}=P_{a}-F_{a}-S_{i n}-P E T-D_{s}
$$

where $R_{\mathrm{a}}$ accumulated surface runoff in $\mathrm{mm}, P_{\mathrm{a}}$ accumulated precipitation in $\mathrm{mm}$, $F_{\mathrm{a}}$ accumulated infiltration in $\mathrm{mm}, S_{\text {in }}$ interception storage in $\mathrm{mm}$, PET potential evapotranspiration in $\mathrm{mm}$, and $D_{\mathrm{s}}$ surface depression storage in $\mathrm{mm}$.

The model represents the hydrological processes taking place in catchment as follows:

The falling precipitation is partly intercepted by vegetation. Interception process is simulated according to an equation suggested by Flemming (1979) [9] which is given by

$$
\Delta S_{\text {in }}=\left(P_{d} \times D_{c}\right)-E_{\text {in }}
$$

where $\Delta S_{\text {in }}$ is the change in interception storage per unit area of canopy, when current interception storage is less than maximum storage capacity, $P_{\mathrm{d}}$ is the precipitation depth per unit area of catchment, and $D_{\mathrm{c}}$ is the canopy density, $E_{\text {in }}$ is evaporation and transpiration from interception storage per unit area.

Interception storage $S_{\text {in }}$ is depleted by evapotranspiration PET. When interception storage is satisfied, the excess water (throughfall) flows to the ground surface. Throughfall is estimated by the following equation

$$
T_{\text {in }}=S_{\text {in }}+\Delta S_{\text {in }}(t)-S_{\max }
$$


where $T_{\text {in }}$ is throughfall in excess of interception storage capacity, $\mathbf{S}_{\mathbf{i n}}$ is interception storage at time $(t-1)$, and $S_{\max }$ is the maximum interception storage capacity.

When throughfall and other rain reach the ground surface, it infiltrates into the soil to augment soil moisture storage. Infiltration rate is taking place according to Holton equation [10], which is given by

$$
f=a(S a)^{n}+f_{c}
$$

where $f$ is infiltration capacity rate in $\mathrm{mm} / \mathrm{h}, S a$ is the available storage capacity depth in the surface layer in $\mathrm{mm}$. At the beginning of infiltration, $S a$ is usually at its initial value $S a_{\mathrm{i}}\left[S a_{\mathrm{i}}\right.$ is the first model parameter], $a$ and $n$ are the intercept and slope, respectively, of a algorithmic plot of the quantity $\left(f-f_{\mathrm{c}}\right)$. Vs. $S a[a$ and $n$ are the second and third model parameters $], f_{\mathrm{c}}$ is the constant infiltration rate in $\mathrm{mm} / \mathrm{h}\left[f_{\mathrm{c}}\right.$ is the fourth model parameter). If water reaches the ground surface at a rate greater than infiltration capacity rate, then the water in excess of infiltration capacity rate augments surface depression storage $D_{\mathrm{s}}$. At the same time, this storage is depleted by evaporation $E_{\mathrm{r}}$ and infiltration $F_{\mathrm{a}}$.

When surface depression storage exceeds its threshold $D_{\max }\left[D_{\max }\right.$ is the fifth model parameter] direct surface runoff DRO takes place and is computed according to the following equations

$$
\begin{gathered}
D R O=P_{d}-\left(S_{c i}+f . \Delta t+D_{c}\right) ; F O R P_{d}>\left(S_{c i}+f . \Delta t+D_{c}\right) \\
D R O=0 ; F O R P_{d} \leq\left(S_{c i}+f . \Delta t+D_{c}\right)
\end{gathered}
$$

where DRO is direct surface runoff in $\mathrm{mm}, S_{\mathrm{ci}}$ is the capacity depth of inflow into interception storage in $\mathrm{mm}$ for each time increment, and $D_{\mathrm{c}}$ is the capacity depth of inflow into surface depression storage for each time increment.

Soil moisture storage is augmented by infiltration and depleted by evapotranspiration. When it reaches its threshold (field capacity, $F C$ ) percolation and subsurface flow commence. The model assumed that percolation is taking place at a rate smaller than $f_{\mathrm{c}}$. Subsurface flow is estimated according to the following restriction

$$
\begin{gathered}
\text { IF }\left(S a<\operatorname{Grav}_{w}\right) \text { and } S W>f_{c} \cdot \Delta t, \text { THEN SSF }=S_{c} .(S W-P E R) \\
\text { IF }\left(S a<\operatorname{Grav}_{w}\right) \text { and } S W \leq f_{c} . \Delta t, \text { THEN SSF }=0
\end{gathered}
$$

where $\mathrm{Grav}_{\mathrm{w}}$ is gravitational water in $\mathrm{mm}$, SSF is sub-surface flow in $\mathrm{mm}$ for each time increment, and $S_{\mathrm{c}}$ is coefficient of subsurface flow $\left[S_{\mathrm{c}}\right.$ is the sixth model parameter].

Subsurface flow SSF augments continuously surface depression storage. If the latter exceeds its threshold, surface runoff occurs. The recovery of moisture storage capacity between the periods of rain may be estimated as follows 


$$
S a_{t}=S a_{t-1}-\Delta F_{t-1}+\mathrm{PER}_{t-1}+\mathrm{SSF}_{t-1}+\mathrm{PET}_{t-1} \cdot \Delta t
$$

where PET is the potential evapotranspiration rate in $\mathrm{mm} / \mathrm{h}, \mathrm{PER}$ is percolation in $\mathrm{mm}$, SSF is subsurface flow in $\mathrm{mm}, \Delta t$ is time increment in hrs, and $t$ is a time index.

The recession curve represents withdrawal from storage within the catchment. The general equation used to describe the recession curve is expressed as follows

$$
Q_{t}=Q_{0} \times K_{r}
$$

where $Q_{0}$ is the flow at any time in cumecs, $Q_{t}$ is the flow one time unit later in cumecs, and $K_{\mathrm{r}}$ is the recession constant $\left[K_{\mathrm{r}}\right.$ is the seventh model parameter].

The absorb basin time for each applied storm is calculated by accumulating the time step from the start of rain till the runoff commences.

The proposed model uses the time-area method to transform the effective storm hyetograph into a runoff hydrograph. The general nonlinear time-area curve obtained for the catchment under study is given by

$$
\mathbf{A}=35.38 \mathbf{T}_{\mathbf{c}}^{\mathbf{1 . 8 3}}
$$

where $A$ is the watershed area, where its boundary is from the Wade outlet to the most remote point of surface runoff movement on this area, in $\mathrm{km}^{2}, c \& d$ are regression coefficients and $T_{c}$ is the time of concentration. The number of wetted areas $N A$ for each storm is determined by using optimization technique [NA is the eighth model parameter].

Eq. (11) is used to compute accumulated wetted sub areas for each accumulated time of concentration. Each sub area is multiplied by rainfall excess array, resulting from catchment water balance. The result will be the surface runoff at the outlet of the wetted area. This yields a set of linear equations which can be expressed in matrix form as

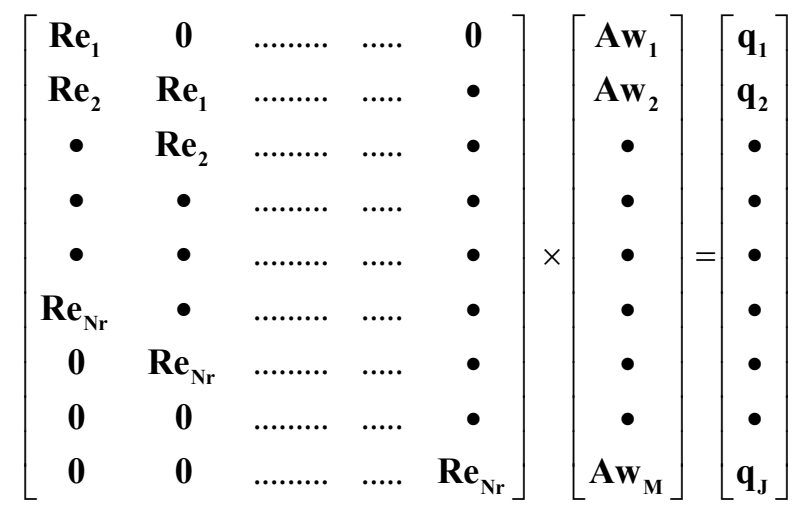

Or

$$
[R e] \times[A w]=[q]
$$


where $[\mathrm{Re}]$ is the rainfall excess array in $\mathrm{mm} / \mathrm{h},[\mathrm{Aw}]$ is watershed wetted sub area column vector in $\mathrm{km}^{2},[q]$ is wetted area outflow discharge column vector, Nr is number of ordinates of rainfall excess, $M$ is number of wetted sub area, and $J$ is an index.

For assessing model performance, the well known least square objective function is used. It is given by

$$
O F(L S)=\frac{\sum_{i=1}^{N}\left(Q_{0 b s_{i}}-Q s i m_{i}\right)^{2}}{N}
$$

where $Q_{o b s}$ is the observed average flow at any day $i, \operatorname{sim}_{\mathrm{i}}$ is the simulated flow on any day $i$, and $N$ is the total number of days. The least square objective function evaluates the sum of flow residual. The value of $O F$ should be close to zero for a good simulation. An auxiliary approach to optimization is the use Nash efficiency criterion [11] given by

$$
R^{2}=100\left[1-\frac{\sum_{i=1}^{N}\left(Q_{o b s_{i}}-\mathrm{Qsim}_{i}\right)^{2}}{\sum_{i=1}^{N}\left(\mathrm{Qobs}_{i}-\overline{\left.\mathrm{Qobs}^{2}\right)^{2}}\right.}\right]
$$

where $\overline{\mathrm{Qobs}_{\mathrm{i}}}$ is the observed streamflow over the calibration period $N$. A perfect agreement between the observed and simulated flow yields a value of $R^{2}$ closer to $100 \%$, whilst a negative $R^{2}$ represents a lack of agreement worse than if the simulated flows are replaced with the observed flow. In this study, shuffle complex evolution global optimization method (SCE.UA) developed by Duan et al. [12] is used for calibrating the model parameters.

The data for the simulation example in this study were collected from one ephemeral semi-arid catchment located at the central part of Jordan; the name of this catchment is Wadi Wala; its area is approximately $1770 \mathrm{~km}^{2}$. This catchment is about $60 \mathrm{~km}$ southwest of Amman city; the name of this catchment is Wadi Wala catchment; the location of this catchment is shown in Figure 2. Its area is approximately $1770 \mathrm{~km}^{2}$ mainly of plateau land to the east of the Dead Sea.

The climate of Wala catchment is predominantly considered to be under the influence of the East Mediterranean sea with cold wet winter and hot dry summer. Orographic precipitation and convective thunder storms have been recorded at Wala catchment especially at the beginning and or at the end of winter seasons, causing sharp peaks of flashy floods because of the high intensity of rainfall.

The detailed soil characteristics are not available for the catchment under study; therefore, the properties of this soil are estimated from soil properties classified by Rawls et al. [13].

The hydrological and meteorological data for Wala catchment were collected from unpublished files of the Water Authority of Jordan (WAJ). These data are considered to some extent sufficient for fitting the model parameters. Hourly rainfall data were obtained for a period (1990-2001). The data were available for three different recording rainfall stations located at different sites within Wala catchment. 


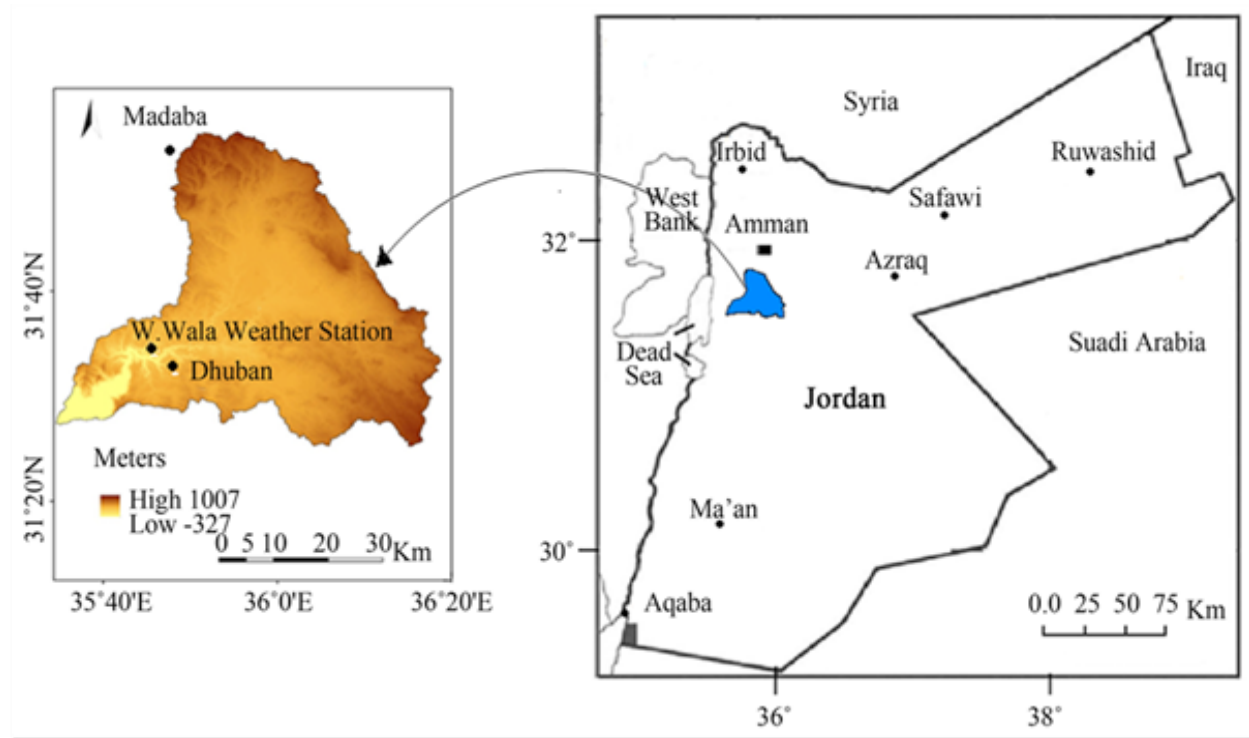

FIGURE 2. Location map of the test catchment.

\section{Results}

Generally simulation results show a good agreement between observed and simulated hydrographs. This is clearly shown in subsequent figures, which are drawn to illustrate the calibration and validation processes.

Nash efficiency criterions $R^{2}$ are provided with all figures to provide an indication on performance of the simulation process. Figure 3 illustrates clearly the continuous observed and optimized hydrographs for a selected four storms of Wala catchment.

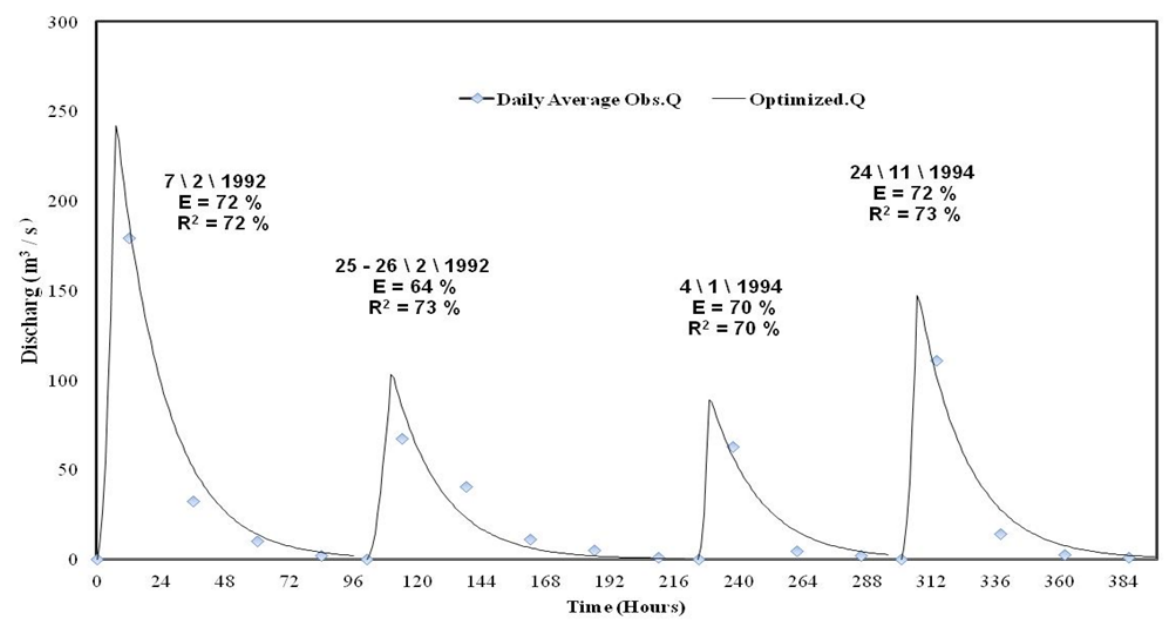

FIGURE 3. Observed and optimized hydrographs for a selected four storms of Wadi Wala catchment. 
Modeling Rainfall Runoff Relations at Arid Catchments Using Conceptual Hydrological Modeling Approach

The storms were inserted into the model continuously so that the resulted optimal parameters will represent the average of all events. The values of $R^{2}$ range from 70 to $73 \%$. The coefficient of efficiency, $E$ range from 64 to $72 \%$.

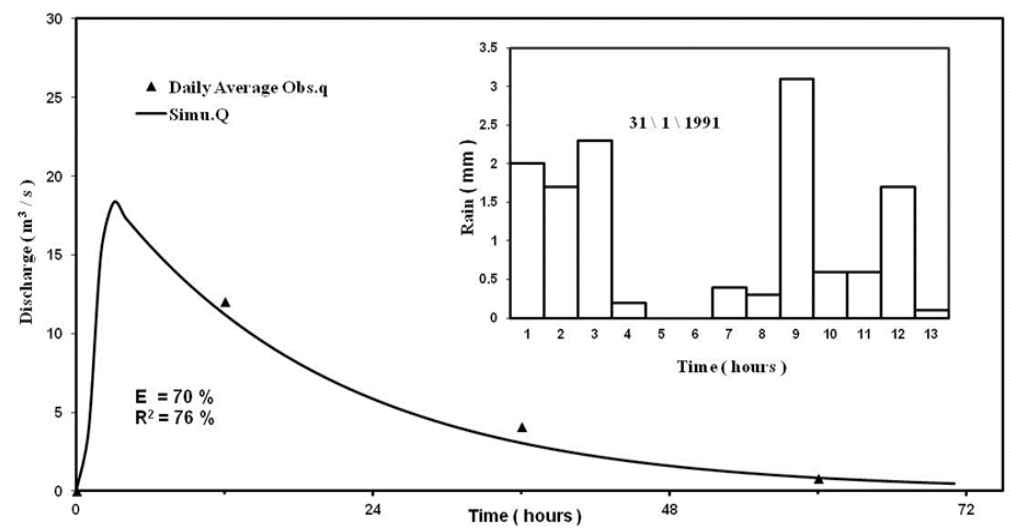

(a)

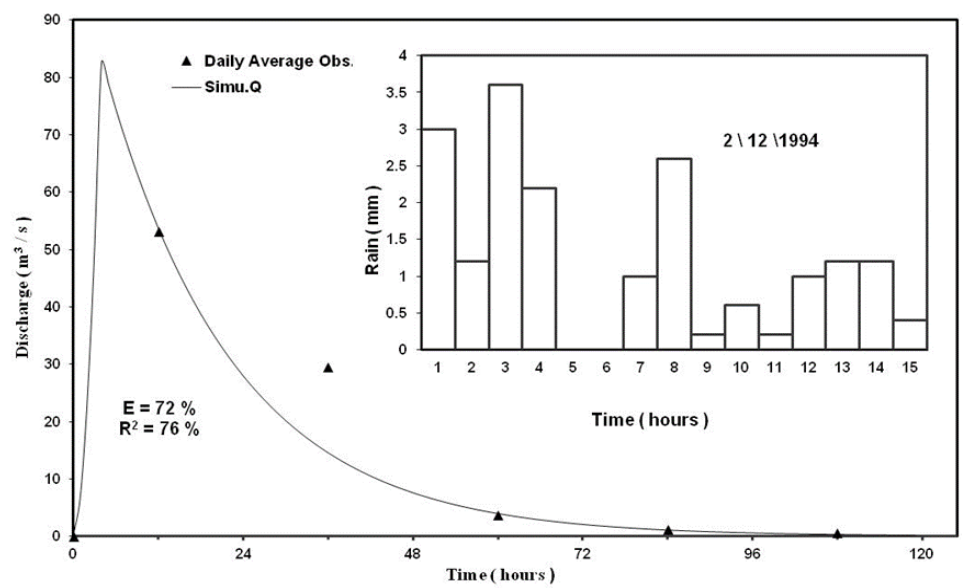

(b)

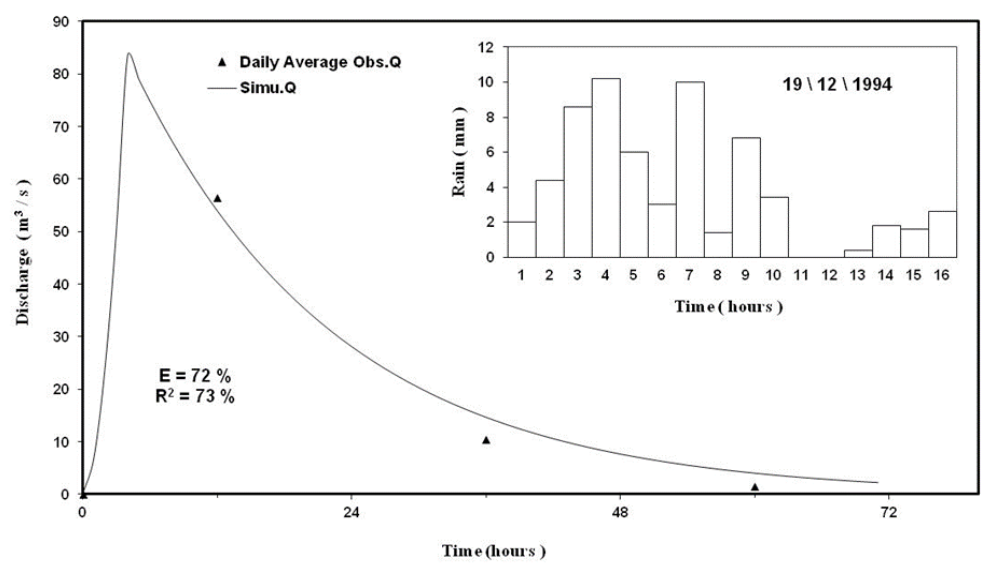

(c) 


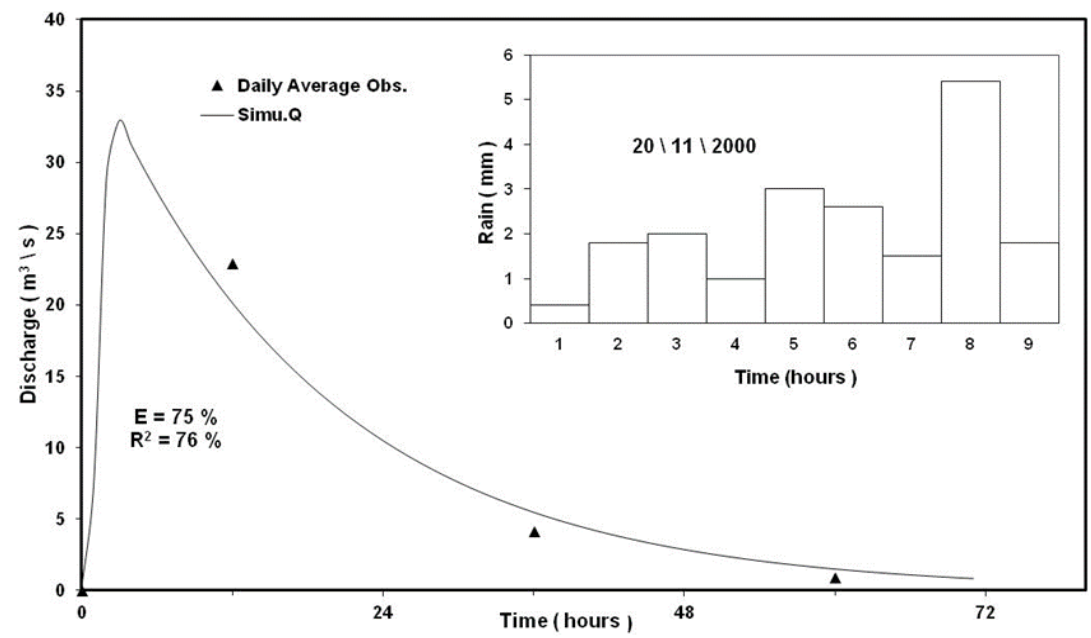

(d)

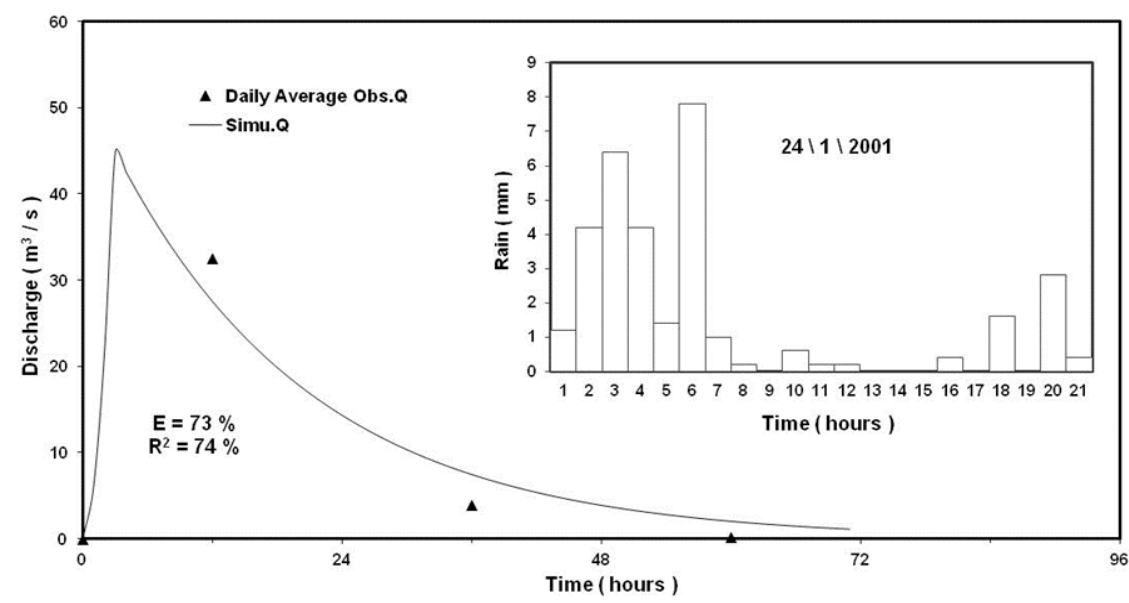

(e)

FIGURE 4. a. Observed and simulated discharge for Wadi Wala catchment [Storm event 31/01/1991]. b. Observed and simulated discharge for Wadi Wala catchment [Storm event 2/12/1994]. c. Observed and simulated discharge for Wadi Wala catchment [Storm event 19/12/1994]. d. Observed and simulated discharge for Wadi Wala catchment [Storm event 20/11/2000]. e. Observed and simulated discharge for Wadi Wala catchment [Storm event 24/1/2001].

Similarly, Figure 4a-e shows the results of validation process in which observed and simulated hydrographs are graphically compared. The $R^{2}$ values of all storms used in validation range from $73 \%$ to $76 \%$ and the coefficient of efficiency, $E$ range from 70 to $75 \%$. Rainfall hyetographs for all storms employed in validation are also provided in the same figures.

The parameters of the proposed model along with their optimum values are all provided in Table 1. 
Modeling Rainfall Runoff Relations at Arid Catchments Using Conceptual Hydrological Modeling Approach

TABLE 1. Optimized parameter values for the catchment under study

\begin{tabular}{lcccccccc}
\hline Parameter & $\begin{array}{c}\mathbf{S a}_{\mathbf{i}} \\
(\mathrm{mm})\end{array}$ & $\boldsymbol{a}$ & $\boldsymbol{n}$ & $\begin{array}{c}\boldsymbol{f}_{\mathrm{c}} \\
(\mathrm{mm} / \mathrm{h})\end{array}$ & $\begin{array}{c}\boldsymbol{D}_{\max } \\
(\mathrm{mm})\end{array}$ & $\boldsymbol{S}_{\mathrm{c}}$ & $\boldsymbol{K}_{\mathbf{r}}$ & NA \\
\hline Lower bound & 0.0 & 0.08 & 0.1 & 1.27 & 10 & 0.0 & 0.1 & 1.0 \\
Upper bound & $\mathrm{TP}$ & 0.9 & 1.5 & 3.8 & 50 & 0.9 & 0.99 & $\mathrm{Tc} * \Delta \mathrm{t}$ \\
Optimum value & 22 & 0.33 & 0.10 & 1.30 & 10.00 & 0.55 & 0.93 & 4 \\
\hline
\end{tabular}

\section{Conclusions}

Based on the results obtained on this study, the following conclusions are drowned:

1. A good $R^{2}$ values obtained in both calibration and validation is sufficient to claim that the proposed model is capable to represent the hydrological process taking place in the catchment and also to measure catchment response to an admissible range of accuracy.

2. In this study, the parameter " $f_{c}$ " is taking value equal to its lower constraint. The ratiocination of this is that the dominant soil texture for the studied catchment is silty clay loam which is considered as heavy soil and, according to the hydrologic soil groups; this soil has a lower infiltration rate as compared to other types of soil. In a arid and semi-arid catchment both temporal and spatial variability is mainly controlled by the physical and chemical properties of the soil surface (Vaezi et al. 2010) [14].

3 . This is true. The values of infiltration parameters " $a$ " and " $n$ " are somewhat apart. The difference between the values of " $a$ " and " $n$ " can be neglected because any increase or decrease in the value of parameter " $n$ " is compensated by the same amount in the value of parameter " $a$ " and vice versa. The optimized value of parameter $D_{\max }$ is taking its lower bound value. The lower value of $D_{\max }$ may be attributed to the catchment higher relief and its steeper slope.

4. The optimized values of parameters $S a_{\mathrm{i}}$ and NA provided in Table 1 are taking as the average values for all storms used in calibration. $S a_{\mathrm{i}}$ tend to take its optimum value near to its lower bound. This lower value reflects the effect of soil condition at the catchment which remain dry for most the year. Similarly, NA takes an optimum value equal to $50 \%$ of its upper bound. This is near to the actual situation where, convective thunder storms cover only part of the catchment and most its area remain dry.

5. Recession co-efficient, $K_{\mathrm{r}}$ is somewhat taking greater value. This parameter depends mainly on catchment characteristics (such as soil type and catchment relief). The higher value of $K_{\mathrm{r}}$ may be attributed to the steep slope of the catchment main channel, another reason for high value of $K_{\mathrm{r}}$ is the nature of streamflow data used in calibration, the data are provided at daily time interval and this has produce an hourly simulated hydrograph, most of its time base fall under the recession curve.

\section{References}

1. Mroczkowski M, Raper GP, Kuzera G. The quest for more powerful validation of conceptual catchment models. Water Resources. Research. 1997; 33(10), 2325-2335. 
2. Crawford NH, Linsley RK. Digital simulation in hydrology. Stanford watershed model IV, Stanford University Dept.Civil Engr, Tech Report 39. 1966.

3. Chiew FHS, Mc Mahon TA. Application of the daily rainfall-runoff model MODHYDROLOG to 28 Australian catchments, Journal of Hydrology. 1994; 153, 383-416.

4. Jakeman AJ, Littlwood IG, Whitehead PG. Computation of the instantaneous unit hydrograph and identifiable flows with application to two small catchment, Journal of Hydrology. 1990; 117, 275-300.

5. Yasmin Ytoui, Ranfall- runoff modeling at monthly and daily scales using conceptual models and Nero-Fuzzy inference system. $2^{\text {nd }}$ international conference on water resources and wetland, Tuclca, Romania, Peter Bretcan. 2014. ISSN: 2285-7923,263-270.

6. Pilgrim DH, Chapman TG, Doran DG. Problems of rainfall-runoff modelling in arid and semiarid regions, Hydrological Sciences Journal. 1988; 33(4), 379-400.

7. Sharma KD, Sorooshian S, Wheater H. Hydrological modelling in arid and semi-arid areas. Cambridge University Press: New York. 2008, 223. ISBN-13 978-0-511-37710-5.

8. McIntyre N, Al-Qurashi A, Wheater HS. Regression analysis of rainfall- runoff events from an arid catchment in Oman. Hydrological Sciences Journal. 2007; 52(6), 1103-1118.

9. Flemming G. Deterministic model in hydrology, Food and Agriculture Organization of the United Nation, Irrigation and drainage paper No.32.Rome. 1979.

10. Holtan HN.A concept for infiltration estimates in watershed engineering. "U.S. Dept. Agr., ARS14-51, Washington, D.C. 1961.

11. Nash JE, Sutcliffe JV. River flow forecasting through conceptual models. Journal of Hydrology. 1970; 10(3), 282-290.

12. Duan Q, Sorooshian S, Gupta VK. Effective and efficient global optimization for conceptual rainfall-runoff models. Water Resources Research. 1992; 28(4), 1015-1031.

13. Rawls WJ, Brakensiek DL, Saxton KE. Estimation of soil water properties. Transactions of the ASAE. 1982; 25, 1316-1320.

14. Vaezi AR, Bahrami HA, Sadeghi SH, Sadeghi R, Mahdian MH. Modeling relationship between runoff and soil properties in dry-farming lands, NW Iran. Journal Hydrology and Earth System Sciences (HESS). Discuss. 2010; 7, 2577-2607. 